Original research article

\title{
Effectiveness of peer education approach on improving HIV/AIDS related healthy behaviors among immigrant street children: A randomized controlled trial
}

\author{
Nasim Khosravi ${ }^{a}$, Goodarz Kolifarhood ${ }^{\mathrm{b}}$, Alireza Shoghlic,*, Shahrzad Pashaeypoor ${ }^{\mathrm{d}}$, \\ Morteza Amlashi ${ }^{\mathrm{e}}$ \\ a Department of Community Health Nursing, School of Nursing and Midwifery, Tehran University of Medical Sciences, Tehran, Iran \\ b Department of Epidemiology, School of Public Health, Shahid Beheshti University of Medical Sciences, Tehran, Iran \\ ${ }^{\mathrm{c}}$ Social determinants of health research center, Social medicine department, Zanjan University of Medical Sciences, Member of National Committee on \\ Monitoring and Evaluation of HIV/AIDS, Tehran, Iran \\ d Department of Community Health Nursing, School of Nursing and Midwifery, Tehran University of Medical Sciences, Tehran, Iran \\ e Independent Consultant, United Nations Development Program office (UNDP), Tehran, Iran,
}

\section{A R T I C L E I N F O}

\section{Article history:}

Received 15 July 2017

Received in revised form 16 September 2017

Accepted 22 September 2017

Available online 22 September 2017

\section{Keywords:}

Street children

immigrant

peer education

HIV/AIDS

\begin{abstract}
A B S T R A C T
Objective: Foreign-origin street children are vulnerable to HIV/AIDS mainly due to poverty, violence, early sexual activity and poor access to health care services. This study aimed to highlight the effectiveness of peer education intervention to reduce HIV-risky behavior among street children with Afghan nationality. Methods: Sixty-one street children were stratified by sex and then randomly allocated to either an intervention or control group by assigning each participant computerized random numbers. The intervention provided peer education services, focused on mode of disease transmission, prevention approaches and awareness of HIV/AIDS services by peers.

Results: At least $80 \%$ of participants in the intervention and control groups completed the study period, respectively. At the end of the study, statistically significant increase of knowledge and attitude improvement as well as a decreased tendency to do risky sexual intercourse among the intervention subjects was shown. Moreover, there was a time intervention interaction for knowledge and attitude improvements followed by intervention (interaction p value $=0.001$ ), while it was not significant for risky sexual behavior (interaction p value $=0.44$ ).

Conclusion: Peer education was an effective and easy-to-apply educational method that increased knowledge and improved attitudes about HIV/AIDS among foreign-origin street children, while it was less efficient with regard to long-term reduction in risky sexual behavior.
\end{abstract}

(C) 2017 Published by Elsevier, a division of RELX India, Pvt. Ltd on behalf of INDIACLEN.

\section{Introduction}

Poor knowledge, wrong beliefs, and risky behavior among street children potentially expose them to HIV/AIDS infection. ${ }^{1-3}$ In comparison to other general teenage populations, street children are more vulnerable to HIV/AIDS mainly due to poverty, violence, immigration from low-income countries, early sexual activity and

\footnotetext{
* Corresponding author at: Haj mahdavi Blv, Shahrak Karmandan, Department of Social Medicine, Zanjan Medical School, Zanjan, Iran.

E-mail addresses: nasimkhosravi.khosravi3@yahoo.com (N. Khosravi), gfarhood@gmail.com (G. Kolifarhood), shoghli@yahoo.com (A. Shoghli), Pashaeypoor.sh@gmail.com (S. Pashaeypoor), amlashi@gmail.com (M. Amlashi).
}

poor access to health care services. ${ }^{4-10}$ According to World Health Organization report (2000), there are about 100 million street children in the world of whom the majority spend most of their time on streets. ${ }^{11}$ According to official reports, there are an estimated number of 200,000 street children in $\operatorname{Iran}^{6,12}$ of whom more than fifty percent are Afghan illegal refugees. ${ }^{13,14}$ Global prevalence rate of HIV/AIDS among street children is variable and it is ranged from $2 \%$ in Canada to $37.4 \%$ in Russia. ${ }^{15}$ The exact prevalence rate of HIV/AIDS among street children in Iran is unknown. Results of a survey on HIV seroprevalence in Tehran showed at least $5 \%$ of street children were infected with HIV. ${ }^{14}$ However, it would be expected that the number of children who are infected with HIV are higher than national figures. ${ }^{16}$ 
HIV prevention studies that have focused on street children are limited and most studies involving street youth have estimated the incidence and prevalence of risky behavior rather than evaluating preventive interventions and their challenges. ${ }^{17,18}$ Furthermore, the cost-effectiveness of HIV/AIDS preventative approaches is a big challenge toward the generalizability of successful interventions, particularly in Low to Middle Income Countries (LMICs). ${ }^{19}$ In this way, a few studies implied that higher financial allocations for school-based education and Voluntary Counseling and Testing (VCT) yield better outcomes. ${ }^{20}$

Among the several community-based educational models, peer education is known as an efficient approach to raise awareness and also better access to HIV/AIDS services for hard-to-reach populations. $^{21,22}$ Therefore, we set out this randomized controlled trial to assess peer education approach effects on HIV/AIDS knowledge and attitude improvement, reduction in risky behavior as well as this approach's feasibility among non-illegal Afghan immigrant street children.

\section{METHODS}

2.1. Study population and health service utilization among Afghan immigrants

Iran as a middle-income country is located in Eastern Mediterranean region with a population of 80 million. ${ }^{23}$. This country is the main destination for Afghan refugees whose main purpose for immigration is to seek better opportunities for life, which seems to be a consequence of the long-lasting war in Afghanistan. ${ }^{24}$ Based on official reports, the majority of immigrant populations in Iran has been comprised of people with Afghan nationality (at least 1.2 million people), of whom $39 \%$ are less than 15 years of age. ${ }^{25}$ Notably, a large number of immigrants with

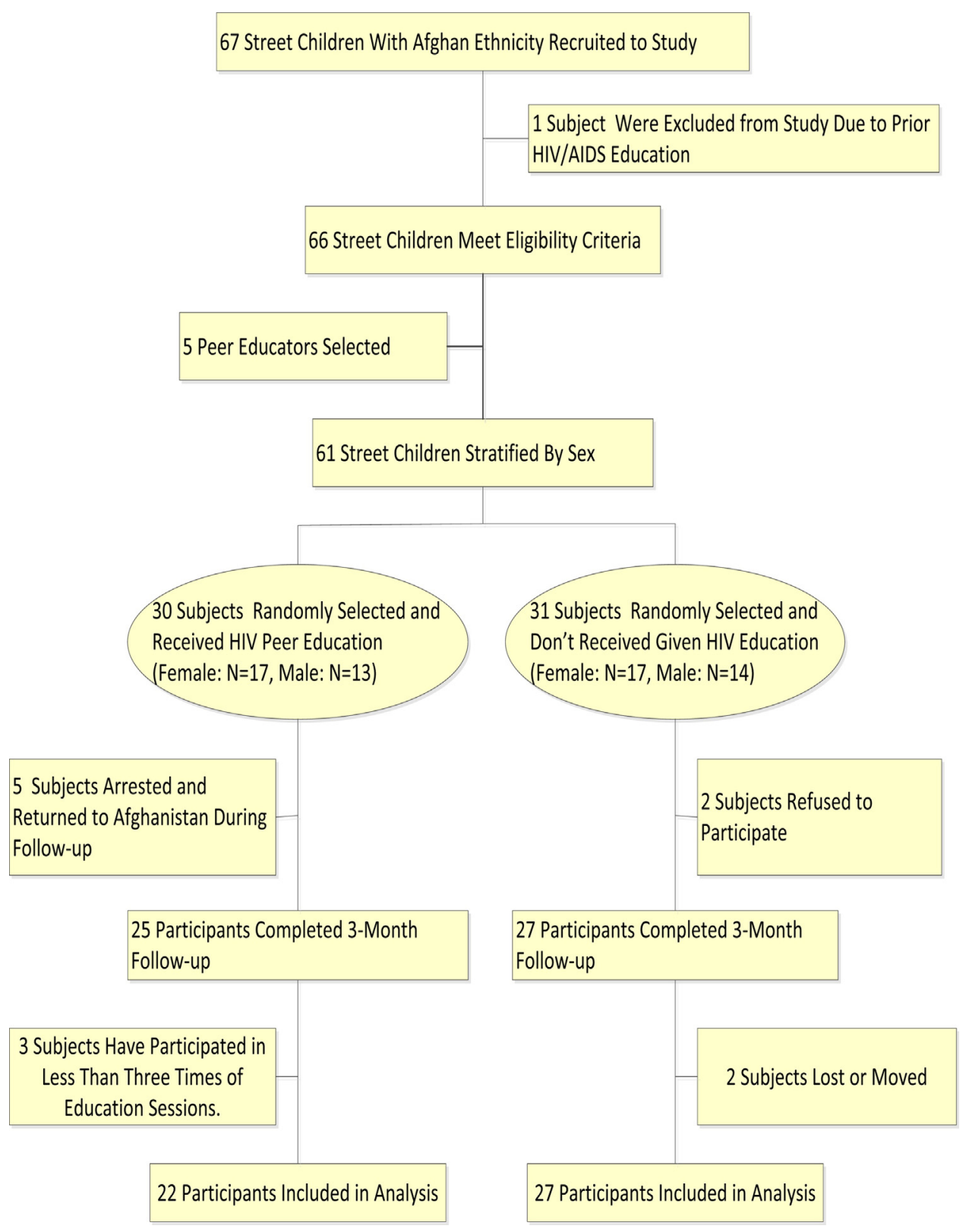

Fig. 1. HIV/AIDS and peer education flow diagram. 
Afghan origin are unauthorized, which deprives them of health services and other social benefits. ${ }^{26}$ The present study was undertaken in Karaj (the largest district of Alborz province) where more than $95 \%$ of street children are Afghan. ${ }^{13,27}$

\subsection{Study design and location of data collection}

In this randomized controlled trial, we recruited a total number of 67 street children with Afghan nationality who received some educational supports by Kiana Street Children Center. The Kiana center, as a Non-Governmental Organization (NGO), was founded to offer educational opportunities, as well as literacy, for street children who are deprived of essential schooling.

\subsection{Eligibility criteria for participants}

Street children are defined as those of 14-18 years old who spend the majority of their time on the streets to work or prowl and return to their families or residences at night. Through baseline interviews, study subjects with a prior training for HIV/AIDS as well as those without minimum skills of reading and writing in Persian, were excluded.

\subsection{Blinding}

The study participants, research team and institutions' staff involved in this project were blinded to intervention assignment. To protect confidentiality, specific numeric codes were assigned to participants before beginning the study.

\subsection{Data collection instrument and baseline measurement}

At baseline, all study subjects were informed about the study aim, intervention protocols and the right to refuse to participate in the study. Then, written and verbal informed consent was obtained from participants and the relevant authorities at Kiana. Using questionnaires (Appendix 1) that were adapted from questionnaires for behavioral surveillance surveys by Family Health International $(\mathrm{FHI})^{28}$ and validated in several national studies in Iran, ${ }^{14,29,30}$ knowledge, attitude and risky behaviors in the context of HIV/AIDS were assessed among study participants. The integrated questionnaires included five main components with questions to cover aspects related to child's socio-demographic characteristics, high-risk behavior (such as alcohol consumption, smoking, substance abuse, drug injection and sexual activity) and also knowledge, attitude and behavior toward HIV/AIDS.

\subsection{Peer educator selection process and content of training program}

There were clear qualitative criteria to select peer educators and it was processed in consultation with the street children's supervisor at the Kiana Institute. These criteria include easy accessibility, known for reliability, and ability to make efficient connections with the other street children. Accordingly, we trained five peers for HIV/AIDS through four separate sessions with a selfadministrated education protocol which was focused on the nature of the disease, mode of transmission, prevention methods, free of charge HIV/AIDS services, and how to communicate and teach their friends. Using a checklist by the research team, last session was devoted entirely for qualitative assessment of educational competency of selected peers through their lectures and brochure presentations. The intervention subjects were divided into five subgroups (each subgroup consisted of six subjects plus one peer) and were trained by peers for up to four weeks (one-hour session per week). The control group participants also were trained for HIV/AIDS by the research team at the end of study period after they were evaluated for Pre-specified outcomes.

\subsection{Sample size}

Considering type I error $(\alpha)=0.05$, power $(1-\beta)=0.8$, and means and standard deviation of knowledge the experimental and control group equal to 83,76 and 10 respectively, the number of 68 samples (34 subjects per each group) was determined as an adequate sample size by PS software. ${ }^{31}$

\subsection{Method used to generate the random allocation sequence}

Through a blocked randomization approach, 61 eligible participants were stratified by sex, and then, by assigning computerized random numbers, they were separated into two groups, intervention and control (Fig. 1).

\subsection{Follow up}

To complete the training program, the intervention and control groups were followed up for three months during the initial phase of the study. Finally, about $75 \%$ and $90 \%$ of the participants in intervention and control groups took part in the entire study period, respectively. Training sessions were held on holidays for the intervention group whenever staff was not present at the institute.

\subsection{Pre-specified primary and secondary outcomes}

Using the same questionnaires at baseline, effects of intervention concerning knowledge enhancement and attitude improvement toward HIV/AIDS, as well as reduction in engaging in risky behavior were evaluated for all participants at the end of completion of the study period.

\subsection{Statistical analysis protocol}

Patients are normally analyzed within the group to which they were allocated, irrespective of whether they experienced the intended intervention (intention to treat analysis). In an attempt to highlight intervention effects, several comparative analyzes were performed by SPSS, version 18 . The final scores were the average scores within questionnaires for knowledge, attitude, and risky sexual behavior. The higher scores for knowledge and attitude represent more awareness and better attitude toward HIV/AIDS, and conversely, the lower scores for tendency to risky sexual behavior indicates safe sexual activity. Accordingly, the distribution of knowledge, attitude and risky sexual behavior scores were checked for normality using Kolmogorov-Smirnov test for each group, separately. Chi-squared and Fisher's exact tests were used to compare expected frequencies corresponding to the observed frequencies between two randomized groups for socio-demographic characteristics, tendency toward substance abuse, as well as engaging in the use of VCT center services. Main effect of training on the knowledge, attitude and tendency to do risky sexual behavior as well as time interaction through intervention was computed by a Generalized Linear Model (GLM) univariate procedure.

\subsection{Ethics}

We obtained ethical verification from the ethical board of the Tehran University of Medical Sciences. In addition, we obtained 
permission from the Kiana Institute authorities after explaining the study aims and procedures.

\section{Results}

Table 1 presents the distribution of socio-demographic characteristics and predisposing factors of HIV/AIDS transmission by category of study groups at baseline. Participants' mean age between two intervention and control groups was distributed with similar standard deviations. Around two-thirds of participants stated that they had never heard about HIV/AIDS and one-fourths of participants declared that they had experienced some degree of emotional, physical, sexual and verbal violence. In addition, at least one out of ten reported having engaged in sexual intercourse. In general, no statistical difference was observed for baseline characteristics, as well as healthy behavior, of participants in study groups.

As shown in Table 2, no difference for frequency of substance abuse (either by inhaling or injecting) was observed at baseline or at the end of the study. Neither participants with an intervention nor the control group were aware of VCTs at baseline, while higher numbers of participants in the intervention group reported the importance of VCTs centers and were willing to refer the center at the end of study.

As presented in Table 3, at baseline, the mean scores of knowledge and attitude among participants in the intervention group were slightly higher than the control group. While tendency for risky sexual behavior was higher among the control group, these findings were not statistically significant. At the end of study, compared to participants in control group, the mean scores of knowledge and attitude about HIV/AIDS in the intervention group were increased by two-fold in comparison to the baseline scores ( $p$ value $=0.001$ and $\mathrm{p}$ value $=0.013$, respectively). Further, the

Table 1

Baseline street children's characteristics by study group.

${ }^{*} \mathrm{P}$ value was calculated by Mann-Whitney test.

\begin{tabular}{|c|c|c|c|}
\hline Street children's characteristics & $\begin{array}{l}\text { Intervention } \\
(\mathrm{n}=30) \\
(\%)\end{array}$ & $\begin{array}{l}\text { Control } \\
(n=31) \\
(\%)\end{array}$ & $\mathrm{P}$ value \\
\hline Age $($ Mean \pm SD) & $14.9 \pm 1.18$ & $15.1 \pm 1.36$ & $0.5^{*}$ \\
\hline \multicolumn{4}{|l|}{ Sex } \\
\hline Boy & $13(43.3)$ & $14(45.2)$ & \multirow[t]{2}{*}{0.8} \\
\hline Girl & $17(56.7)$ & $17(54.8)$ & \\
\hline \multicolumn{4}{|l|}{ A history of arrest by police } \\
\hline Yes & $4(14.3)$ & $4(12.9)$ & \multirow[t]{2}{*}{$0.58^{\ddagger}$} \\
\hline No & $24(85.7)$ & $27(87.1)$ & \\
\hline \multicolumn{4}{|c|}{ A history of being a victim of violence } \\
\hline Yes & $7(24.1)$ & $9(29)$ & \multirow[t]{2}{*}{0.66} \\
\hline No & $22(75.9)$ & $22(71)$ & \\
\hline \multicolumn{4}{|l|}{ A History of tobacco use } \\
\hline Yes & $4(13.8)$ & $7(22.6)$ & \multirow[t]{2}{*}{$0.56^{\ddagger}$} \\
\hline No & $25(86.2)$ & $24(77.4)$ & \\
\hline \multicolumn{4}{|l|}{ Alcohol consumption } \\
\hline Yes & $1(3.7)$ & $1(3.3)$ & \multirow[t]{2}{*}{$0.72^{\ddagger}$} \\
\hline No & $26(96.3)$ & $29(96.7)$ & \\
\hline \multicolumn{4}{|l|}{ Hearing about HIV/AIDS } \\
\hline Yes & $9(32.1)$ & $7(22.6)$ & \multirow[t]{2}{*}{0.4} \\
\hline No & $19(67.9)$ & $24(77.4)$ & \\
\hline \multicolumn{4}{|l|}{ Substance abuse } \\
\hline Yes & 0 & $1(3.2)$ & \multirow[t]{2}{*}{$0.51^{\ddagger}$} \\
\hline No & $29(100)$ & $30(96.8)$ & \\
\hline \multicolumn{4}{|l|}{ Having sexual activity } \\
\hline Yes & $3(11.5)$ & $6(23.1)$ & \multirow[t]{2}{*}{$0.23^{\ddagger}$} \\
\hline No & $23(88.5)$ & $20(76.9)$ & \\
\hline
\end{tabular}

†P values were calculated by Fisher's exact test.

*P value was calculated by Mann-Whitney test. intervention group showed decreased tendency to engage in risky sexual intercourse $(p$ value $=0.025$ ) .

Table 4 shows GLM univariate analysis outputs with regard to main effects of time, intervention and multiplicative interaction of time-group for the knowledge, attitude, and tendency to risky sexual behavior. Accordingly, a significant change in increasing knowledge and improving attitudes was observed through intervention. Neither intervention nor time introduced statistically significant changes in participants' tendency to engage in safe sexual behavior ( $p$ value $=0.066$ and $p$ value $=0.173$, respectively).

Considering knowledge, attitude and risky sexual intercourse, there was a time-intervention interaction so that the slope's difference for either knowledge or attitude was positively shifted. However, there was no significant intervention for the risky sexual behavior in multiplicative scale followed by intervention (Fig. 2).

\section{Discussion}

Findings of the study indicated that intervention by peers among street children is a successful approach to increase knowledge and improve their attitude toward HIV/AIDS. Even though general improvements were made in knowledge and attitude, it did not result in reduce risky sexual behavior. Moreover, having received enough knowledge about VCTs, the provided services were welcomed by participants who were deprived of such services normally. Although the participants in the study groups were no co-intervened with other educational programs about HIV/AIDS prevention over study period provided by media or other sources, an explanation for general improvements of study outcomes in the control relative to baseline suggests this group likely had received some of the initial training from subjects' close relatives or friends in the intervention group.

There is a growing range of evidence that the peer education method could be considered as one of the main prevention approaches in controlling HIV/AIDS epidemics, particularly in countries with poor resources. ${ }^{21,22-30,32-33}$ Furthermore, the peer education approach was introduced as an effective strategy to deal with health promotion among immigrant populations. ${ }^{34}$ Accordingly, the experimental studies that use peer-based training programs in sex workers, Injecting Drug Users (IDUs), homeless youths and prisoners indicated some degree of success. ${ }^{30,35-37}$

Similarly, other experimental studies that evaluated effects of peer education approaches on risky behavior reduction among sex workers, street children and runaway youths, revealed some degrees of success with respect to have safe sex by using condom. $^{38-40}$ Moreover, results of a meta-analysis study, which centered on the peer education effectiveness on HIV prevention in developing countries, was associated with increase in knowledge and condom use, as well as reduction in equipment-sharing among IDUs, while it was less efficient with regard to Sexually Transmitted Infections (STIs). ${ }^{22}$

However, there is limited evidence for peer education effectiveness assessment concentrated on sexual health promotion as well as unwanted adolescent pregnancy prevention for young people in European countries. ${ }^{41}$

Generally, the evaluation of risky behavior changes ensuing knowledge enhancement and attitude improvement in a linear correlation manner seems to be superficial. Although knowledge is a prerequisite to behavior change, it is not enough to explain the extent to which knowledge enhancement has been successfully resulted in avoiding or encouraging given behaviors. ${ }^{42-45}$ While several interventional studies revealed some degree of success in reducing HIV/AIDS related risky behaviors, effectiveness of these approaches likely depends on other related covariates in the context of social and cultural backgrounds. ${ }^{46}$ Accordingly, there is 
Table 2

knowledge, attitude and intention to unsafe sexual behavior by study group.

\begin{tabular}{|c|c|c|c|c|c|c|c|}
\hline \multicolumn{2}{|c|}{ Time outcomes measured } & \multirow{2}{*}{$\begin{array}{l}\text { Knowledge (Mean } \pm \text { Sd) } \\
20 \pm 17\end{array}$} & \multirow{2}{*}{$\frac{P \text { value }}{0.086}$} & \multirow{2}{*}{$\frac{\text { Attitude (Mean } \pm \text { Sd) }}{20 \pm 29}$} & \multirow{2}{*}{$\frac{P \text { value }}{0.18}$} & \multirow{2}{*}{$\begin{array}{l}\text { Intention to risky sexual behavior (Mean } \pm \mathrm{Sd} \text { ) } \\
21 \pm 38\end{array}$} & \multirow{2}{*}{$\frac{P \text { value }}{0.35^{*}}$} \\
\hline Baseline & $\begin{array}{l}\text { Intervention } \\
(\mathrm{n}=30)\end{array}$ & & & & & & \\
\hline & $\begin{array}{l}\text { Control } \\
(\mathrm{n}=31)\end{array}$ & $13 \pm 17$ & & $10 \pm 26$ & & $34 \pm 44$ & \\
\hline \multirow[t]{2}{*}{ End point of study } & $\begin{array}{l}\text { Intervention } \\
(\mathrm{n}=22)\end{array}$ & $86 \pm 18$ & $0.001^{*}$ & $43 \pm 31$ & 0.006 & $6 \pm 23$ & $0.025^{*}$ \\
\hline & $\begin{array}{l}\text { Control } \\
(n=27)\end{array}$ & $27 \pm 24$ & & $19 \pm 28$ & & $29 \pm 41$ & \\
\hline \multirow[t]{4}{*}{$\begin{array}{l}\text { Through study period } \\
\text { (Pre-Post test) }\end{array}$} & $\begin{array}{l}\text { Intervention } \\
\text { Pre }(n=30)\end{array}$ & $20 \pm 17$ & $0.001^{\dagger}$ & $20 \pm 29$ & 0.013 & $21 \pm 38$ & $0.17^{\dagger}$ \\
\hline & $\begin{array}{l}\text { Intervention } \\
\text { Post }\left(\mathrm{n}_{=} 22\right)\end{array}$ & $86 \pm 18$ & & $43 \pm 31$ & & $6 \pm 23$ & \\
\hline & $\begin{array}{l}\text { Control } \\
\text { Pre }(n=31)\end{array}$ & $13 \pm 17$ & 0.002 & $10 \pm 26$ & 0.2 & $34 \pm 44$ & $0.85^{\dagger}$ \\
\hline & $\begin{array}{l}\text { Control } \\
\text { Post }\left(n_{=} 27\right)\end{array}$ & $27 \pm 24$ & & $19 \pm 28$ & & $29 \pm 41$ & \\
\hline
\end{tabular}

"P values were calculated by Mann-Whitney test.

${ }^{\dagger} \mathrm{P}$ values were calculated by Wilcoxon signed rank test.

Table 3

knowledge, attitude and intention to unsafe sexual behavior by study group.

\begin{tabular}{|c|c|c|c|c|c|c|c|}
\hline \multicolumn{2}{|c|}{ Time outcomes measured } & Knowledge (Mean \pm Sd) & $P$ value & $\begin{array}{l}\text { Attitude } \\
(\text { Mean } \pm \mathrm{Sd})\end{array}$ & $P$ value & Tendency to risky sexual behavior (Mean \pm Sd) & $P$ value \\
\hline \multirow[t]{2}{*}{ Baseline } & $\begin{array}{l}\text { Intervention } \\
(\mathrm{n}=30)\end{array}$ & $20 \pm 17$ & 0.086 & $20 \pm 29$ & 0.18 & $21 \pm 38$ & 0.35 \\
\hline & $\begin{array}{l}\text { Control } \\
(n=31)\end{array}$ & $13 \pm 17$ & & $10 \pm 26$ & & $34 \pm 44$ & \\
\hline \multirow[t]{2}{*}{ End point of study } & $\begin{array}{l}\text { Intervention } \\
(\mathrm{n}=22)\end{array}$ & $86 \pm 18$ & 0.001 & $43 \pm 31$ & 0.006 & $6 \pm 23$ & 0.025 \\
\hline & $\begin{array}{l}\text { Control } \\
(n=27)\end{array}$ & $27 \pm 24$ & & $19 \pm 28$ & & $29 \pm 41$ & \\
\hline \multirow[t]{4}{*}{$\begin{array}{l}\text { Through study period } \\
\text { (Pre-Post) }\end{array}$} & $\begin{array}{l}\text { Intervention } \\
\text { Pre }(n=30)\end{array}$ & $20 \pm 17$ & 0.001 & $20 \pm 29$ & 0.013 & $21 \pm 38$ & 0.17 \\
\hline & $\begin{array}{l}\text { Intervention } \\
\text { Post }(n=22)\end{array}$ & $86 \pm 18$ & & $43 \pm 31$ & & $6 \pm 23$ & \\
\hline & $\begin{array}{l}\text { Control } \\
\text { Pre }(n=31)\end{array}$ & $13 \pm 17$ & 0.002 & $10 \pm 26$ & 0.2 & $34 \pm 44$ & 0.85 \\
\hline & $\begin{array}{l}\text { Control } \\
\text { Post }(n=27)\end{array}$ & $27 \pm 24$ & & $19 \pm 28$ & & $29 \pm 41$ & \\
\hline
\end{tabular}

Table 4

GLM univriate analysis of main effects of time, group and interaction of time-group for the knowledge, attitude and tendency to unsafe sexual behavior.

\begin{tabular}{|c|c|c|c|c|c|c|c|}
\hline & Variables & Knowledge (F statistic) & P value & Attitude (F statistic) & $P$ value & Tendency to risky sexual behavior (F statistic) & $P$ value \\
\hline \multirow[t]{3}{*}{ GLM output } & Time & 28.8 & 0.001 & 13.1 & 0.001 & 1.891 & 0.173 \\
\hline & Group & 37.3 & 0.0001 & 8.5 & 0.004 & 3.475 & 0.066 \\
\hline & Time * Group & 16.5 & 0.0001 & 1.2 & 0.001 & 0.584 & 0.447 \\
\hline
\end{tabular}
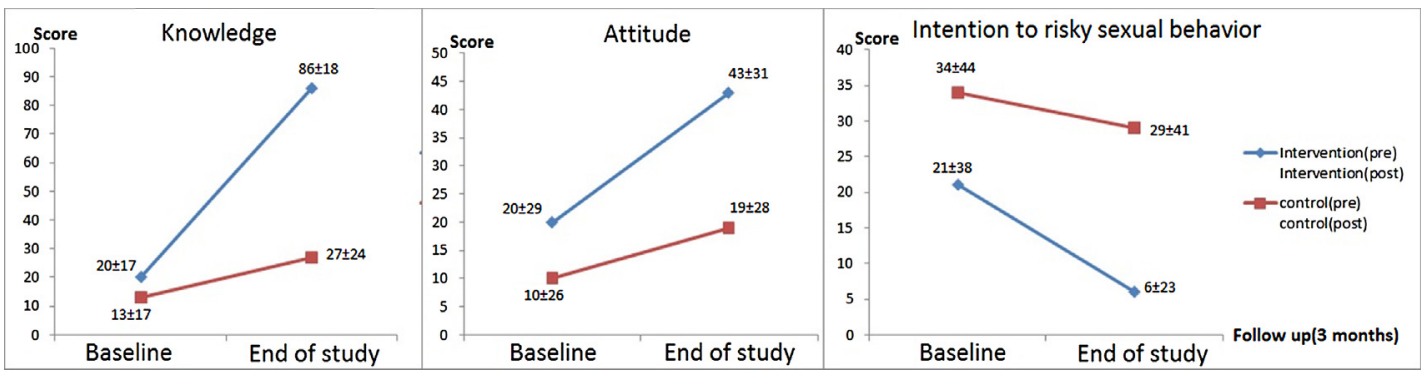

Fig. 2. knowledge, attitude and intention to unsafe sexual behavior changes through study period in intervention and control groups. 
sufficient evidence for peer education effectiveness with regard to changing risky behavior among women of minority racial groups in the United States, ex. "Sisters Informing Sisters about Topics on AIDS (SISTA)" program has been extended nationwide to other age groups, such as adolescents and is facilitated by peers in a community setting. ${ }^{47}$

To our knowledge this study is the first randomized controlled trial in a developing country that explains efficacy of HIV/AIDS training intervention by applying a peer education method in immigrant street children. Nevertheless, the present study faced some limitations. Even though the peer education approach faced minimal challenges to deal with the hard-to-reach population at the NGO institution, a question was remained on representativeness of study samples of which how does it would be deliver in different places where the majority of street children are accessible by peers. In addition, the efficacy of intervention in terms of sustainable outcomes was not evaluated for more than three months after the first training session, hence it can be a potential concern to maintain the positive long-term outcomes. ${ }^{48}$

\section{Conclusions}

Peer education was an effective and easy-to-apply educational method that helped foreign-origin street children to benefit from opportunities to improve their knowledge and attitude toward HIV/AIDS infection. After having received enough knowledge about VCTs through peer-based education, the provided services were welcomed by the participants who were deprived of such services previously. However, this approach would be less effective with regard to reduction in risky sexual behavior in the long term.

\section{Conflict of interest}

None.

\section{Appendix A. Supplementary data}

Supplementary data associated with this article can be found, in the online version, at doi: 10.1016/j.cegh.2017.09.004.

\section{References}

1. Jean-Christophe R, Bhattarai AM, Shrestha B, et al. The street children of Kathmandu: Study, approaches and comments on the daily life of street-based children of the Nepalese capital. Belgium: CPCS NGO (Nepal) and CPCS INT; 2007.

2. Wutoh AK, Kumoji EK, Xue Z, et al. HIV knowledge and sexual risk behaviors of street children in Takoradi, Ghana. AIDS Behav. 2006;10:209-215.

3. Rotheram-Borus MJ, Koopman C. Sexual risk bihaviors, AIDS knowledge and beliefs about AIDS among runaways. Am J Public Health. 1991;81:208-210.

4. Marshall BD, Kerr T, Shoveller JA, et al. Structural factors associated with an increased risk of HIV and sexually transmitted infection transmission among street-involved youth. BMC Public Health. 2009;9(7).

5. Kaime-Atterhög W, Ahlberg BM. Are street children beyond rehabilitation? Understanding the life situation of street boys through ethnographic methods in Nakuru, Kenya. Child Youth Serv Rev. 2008;30:1345-1354.

6. Ahmadkhaniha HR, shooshtari M, Mohammadian M, et al. Street children in Tehran and risk factors for substance abuse. Med J Islamic Republic Iran. 2010;24:83-87.

7. Mathur M, Rathore P. Incidence, type and intensity of abuse in street children in India. Child Abuse Neglect. 2009;33:907-913.

8. Marshall BD, Kerr T, Shoveller JA, et al. Homelessness and unstable housing associated with an increased risk of HIV and STI transmission among streetinvolved youth. Health Place. 2009;15:753-760.

9. Iran Ministry of Health and Medical Education On Monitoring of the United Nations General Assembly Special Session on HIV and AIDS.

10. Mthembu S, Ndateba I. Exploration of knowledge, attitudes and behaviours of street children on the prevention of HIV and AIDS in the Huye district, Rwanda. East Afr J Public Health. 2012;9:74-79.
11. World Health Organization. Working with street children: A training package on Substance use, sexual and Reproductive Health including HIV/AIDS and STDs. Geneva, Switzerland: World Health Organization; 2000.

12. International Labor Organization Clause (d). Direct Request (CEACR) -adopted 2005, published 95th ILC session, Identifying and reaching out to children at special risk: Street children, 2006. Available at: http://www. Iranstreetchildren.com/index.php/article/more/177.SS.

13. Iran Ministry of Foreign Affairs. Islamic Republic of Iran on the Ten-Year Evaluation of Implementing the Commitments Undertaken in the World Summit for Children (WSC), 2000.

14. AR Shoghli, M Mohraz, Biologic-Behavioral Survey of Working/Street Children In Tehran in Connection with HIV/AIDS Infection: National Project Report; MOHME Center for Disease Management, 2010.

15. Noreña-Herrera C, Rojas C, Cruz-Jiménez L. HIV prevalence in children and youth living on the street and subject to commercial sexual exploitation: a systematic review. Cadernos de Saúde Pública. 2016;32(10):e00134315.

16. Fallahzadeh H, Morowatisharifabad M, Ehrampoosh MH. HIV/AIDS Epidemic Features and Trends in Iran, 1986-2006. AIDS Behav. 2009;13:297-302.

17. Beijer U, Wolf A, Fazel S. Prevalence of tuberculosis, hepatitis C virus, and HIV in homeless people: a systematic review and meta-analysis. Lancet Infect Dis. 2012;12:859-870.

18. Mandalazi P, Banda C, Umar E. Street children's vulnerability to HIV and sexually transmitted infections in Malawian cities. Malawi Med J. 2013;25:1-4.

19. Walker D. Cost and cost-effectiveness of HIV/AIDS prevention strategies in developing countries: is there an evidence base. Health Policy Plan. 2003;18:417.

20. Hogan DR, Baltussen R, Hayashi C, et al. Cost effectiveness analysis of strategies to combat HIV/AIDS in developing countries. BMJ. 2005;331:1431.

21. Parkin S, McKeganey N. The Rise and Rise of Peer Education Approaches. Drugs: Educ Prev Policy. 2000;7:293-310.

22. Medley A, Kennedy C, O'Reilly K, et al. Effectiveness of peer education interventions for HIV prevention in developing countries: a systematic review and meta-analysis. AIDS Educ Prev. 2009;21:181-206.

23. Statistical Center of Iran. National portal of statistics. Available at: http://www. amar.org.ir/Portals/0/sarshomari90/n_sarshomari90_2.pdf. (Accessed 1 February 2012)

24. Kadivar MR, Ghaneh-Shirazi R, Khavandegaran F, et al. Epidemiology of Tuberculosis among Afghan immigrants in Fars province, southern Islamic Republic of Iran. East Mediterr Health J. 2007:13:758-764.

25. Statistical Center of Iran. National portal of statistics. Available at: http://amar. org.ir/Portals/2/fileExcell/5.pdf. (Accessed 20 March 2012).

26. Moradi M, Arababadi MK, Hassanshahi G. Tuberculosis in the Afghan immigrant in Kerman province of Iran. J Biol Sci. 2008;8:1107-1109.

27. Vahdani P, Hosseinimoghadam SM, Gachkar L, et al. Prevalence of Hepatitis B, Hepatitis C, Human Immunodeficiency Virus and Syphilis among Street Children residing in southern Tehran, Iran. Arch Iran Med. 2006:9:153-155.

28. Amon J, Brown T, Hogle J, et al. Behavioral Surveillance Surveys: Guidelines for related behavioral surveys in populations at risk of HIV. Family Health International. Section numbers of 1-8, Appendix 1.

29. Shoghli AR, Sedaghat A, Mohajeri M, et al. The study of Adolescent HIV/AIDS knowledge. Attitude and behavior in Iran: National Project Report.

30. Shoghli AR, Rakhshani F, Moosavinasab N, et al. HIV/AIDS-Related Knowledge. Attitude and Behavior of Adolescents and Youth in Select Areas in Iran: National Project Report. .

31. Dupont WD, Plummer WD. Power and sample size calculations: a review and computer Program. Controlled Clin Trials. 1990;11:116-128.

32. Walters AS. HIV Prevention in Street Youth: Review Article. J Adolesc Health. 1999;25:187-198

33. Kirby D, Obasi A, Laris BA. The effectiveness of sex education and HIV education interventions in schools in developing countries. World Health Organ Tech Rep Ser. 2006;938:103.

34. P Drummond, A Mizan, K Brocx, et al., A peer-education model to increase sexual health knowledge in refugees from West Africa. Communicable Disease Control Directorate.

35. Johnson WD, Diaz RM, Flanders WD, et al. Behavioral interventions to reduce risk for sexual transmission of HIV among men who have sex with men (Review). Cochrane Database Syst. Rev. 2008;16(July (3))10.1002/14651858. CD001230.pub2 CD001230.

36. Rietmeijer C, Kane K, Simons P, et al. Increasing the use of bleach and condoms among injection drug users in Denver: outcomes of a targeted communitylevel HIV prevention program. AIDS. 1996;10:291-298.

37. World Health Organization. Effectiveness of interventions to address HIV in prisons. Geneva, Switzerland: World Health Organization; 2007.

38. Laukamm-Josten U, Mzizarubi BK, Outwater A, et al. Preventing HIV infection through peer education and condom promotion among truck drivers and their sexual partners in Tanzania, 1990-1993. AIDS Care. 2000;12:27-40.

39. Shrestha R. Evaluation of HIV/AIDS prevention through peer education, counselling, health care, training and urban refuges in Ghana, UNICEF Ghana. Eval Program Plann. 2002;25:409-420.

40. Rotheram-Borus MJ, Koopman C, Haignere C, et al. Reducing HIV sexual risk behaviors among runaway adolescents. JAMA. 1991;266:1237-1241.

41. Tolli MV. Effectiveness of peer education interventions for HIV prevention, adolescent pregnancy prevention and sexual health promotion for young people: a systematic review of European studies. Health Educ Res. 2012;27:904-913. 
42. M. Adelekan, A critical review of issues around the effectiveness of educational approaches applied in the field of HIV/AIDS prevention. Patient Education and Counseling, Available online 15 December 2015.

43. Mahat G, Scoloveno MA, De Leon T, Frenkel J. Preliminary Evidence of an Adolescent HIV/AIDS Peer Education Program. J Pediat Nurs. 2008;23:358-363.

44. Lou JH, Chen SH. Relationships among sexual knowledge, sexual attitudes, and safe sex behaviour among adolescents: A structural equation model. Int J Nurs Stud. 2009;46:1595-1603.

45. Turner G, Shepherd J. A method in search of a theory: peer education and health promotion. Health Educ Res. 1999;14:235-247.
46. Wyatt GE, Williams JK, Gupta A, Malebranche D. Are cultural values and beliefs included in U.S. based HIV interventions? Prev Med. 2012;55:362-37010.1016/ j.ypmed.2011.08.021.

47. Safren SA, Wingood G, Altice FL. Strategies for Primary HIV Prevention That Target Behavioral Change. Clin Infect Dis. 2007;15(45)S300-30710.1086/ 522554 Suppl 4.

48. Parkin S, Neil McKeganey N. The Rise and Rise of Peer Education Approaches. Drugs: Educ Prev Policy. 2009;7:293-31010.1080/09687630050109961. 